\title{
Media accessibility training
}

\author{
Iwona Mazur \\ Adam Mickiewicz University in Poznan, Poland \\ imazur@wa.amu.edu.pl \\ ORCID: https://orcid.org/0000-0002-7202-2239 \\ Gert Vercauteren \\ University of Antwerp \\ gert.vercauteren@uantwerpen.be \\ ORCID: https://orcid.org/0000-0001-6711-2005
}

\begin{abstract}
With the emergence of media accessibility services such as audio description and (live) subtitles for the deaf and the hard of hearing the need has arisen to train prospective professionals in those areas. In this article, which opens the volume devoted to media accessibility training, we first define the field of study and then review some European projects that deal with the topic. Next, we discuss the current landscape of media accessibility training, including the required skills and competences, curriculum design, methodological approaches, training materials and assessment. An overview of the 12 contributions that have been included in the volume follows, together with an exploration of how they advance the state of the art. Finally, we end with a note on what still remains to be done in the realm of media accessibility training.
\end{abstract}

Keywords: media accessibility training, audiovisual translation didactics, audio description, subtitling for the deaf and the hard of hearing, respeaking

\section{Introduction}

Since the turn of the millennium, accessibility and inclusion have started occupying an ever more prominent position in all sections of society. Policy-makers at both the international and the national level have put these requirements high on their agendas, as evidenced by legislative efforts such as the UN Convention on the Rights of Persons with Disabilities (2006) and the European Accessibility Act (2019).i Broadcasters, museum curators and organizers of cultural events are increasingly providing services such as audio description (AD), subtitling for the deaf and the hard of hearing (SDH) and sign language interpreting (SLI) to make their offerings accessible to the widest possible audiences. In academia, this growing interest has led to the development of a new field within the discipline of (Audiovisual) Translation Studies, namely that of media accessibility (MA). In society at large, this trend has led to the birth of new professions, such as those of the audio describer and the live subtitler. As was the case with other, more traditional forms of audiovisual translation (AVT), such as subtitling and 
Mazur, I., \& Vercauteren, G. (2019). Media accessibility training. Linguistica Antverpiensia, New Series - Themes in Translation Studies, 18, 1-22.

dubbing, these professionals were originally trained in the workplace (Cerezo Merchán, 2019). Universities and other higher-education institutions followed suit and began to include modules in MA as part of their curricula.

Before introducing the various contributions contained in this volume, the present article offers a literature review of MA training and an overview of the research carried out on the topic, including skills and competences, course design, training methodologies, educational materials and assessment. But first we define the field that is the subject of this volume.

\section{Media accessibility training: Definitions}

MA has traditionally been associated with making media and cultural events (such as television, theatre, museums and sports performances) accessible to persons with sensory impairments, whether visual (through $A D$ ) or auditory (through SLI or SDH). Recently proposals have been put forward that extend the notion of (media) accessibility, essentially to avoid a focus on impairments (Greco, 2018; Romero-Fresco, 2018). These proposals look at the different communicative channels present in audiovisual productions and discuss how they can be made accessible to everyone - not only from a sensory perspective but also from a linguistic one. In the process, MA has comes to include many other modes of audiovisual transfer, such as dubbing, voice-over and subtitling. Although we subscribe to this wider view of MA, which is also reflected in the contents of this volume, in this opening article we focus on training in MA in its original conception. Therefore, most of our literature overview concerns training on $A D$ and live SDH through respeaking, as these are the two modes most thoroughly covered in the published literature. We are aware, however, that a vast territory will go uncharted here, such as pre-recorded SDH (which is normally included in subtitling training), live SDH conducted through means other than respeaking (e.g., velotyping, palantyping, stenotyping), $\mathrm{SLI}$ (which is traditionally linked to interpreting) or the creation of easy-to-understand content, which is just beginning to make inroads into MA, for example, through the EASIT project. iii

\section{European projects on media accessibility training}

In response to all of these recent evolutions, institutions of higher education, access service providers and broadcasters all soon realized that dedicated training opportunities were urgently needed: course structures, training materials and even profiles defining the skills and competences of media access professionals were all lacking. In addition to targeted research - which will be covered in the following sections - this led to the launch of various European projects that tried to fill this gap, at both a professional and an academic level.

One of the first projects to address these challenges was ACT, iv which brought together universities, theatres and the cultural departments of local authorities, and ran from 2015 to 2018. It started from the fundamental premise that all people, regardless of any mental, physical, sensory or other disability, should be able to enjoy culture as a prerequisite to taking part fully in society. Although many cultural venues offer some kind of access support, this service is fairly limited and fragmented. One of the reasons for this state of affairs, the project partners argued, is that in most venues no staff member is responsible for guaranteeing and taking care of the accessibility of the venue and its events. In the few instances where such 
Mazur, I., \& Vercauteren, G. (2019). Media accessibility training. Linguistica Antverpiensia, New Series - Themes in Translation Studies, 18, 1-22.

professionals do exist, they have usually not received any specific training in accessibility. Therefore the ACT project proposed to define a new professional profile, namely that of the Media Accessibility Manager for the Scenic Arts. As a first step, the project conducted a survey to form a picture of the current situation and to identify gaps in and the need for access provision. Based on the results of this survey, a comprehensive list of the knowledge, skills and competences that an Accessibility Manager for the Scenic Arts would need was drawn up and a professional profile was defined (see Zhang in this volume). In the next step, learning outcomes were specified and teaching and learning materials for a training course were developed. Since one of the main target groups of the course was people already working in cultural venues and with limited time to work on their professional development - as was confirmed in the survey - a massive open on-line course (MOOC) was created because it offers ample flexibility regarding preferred learning styles, pace and time investment. In addition to the course, the ACT project also created an accessibility label for the scenic arts and, in collaboration with the European Certification and Qualification Agency (ECQA), created a certification scheme for the Media Accessibility Manager (see Romero-Fresco, MelchorCouto, Dawson, Moores, \& Pedregosa, in this volume for a similar endeavour in the field of respeaking).

The approach taken by the ACT consortium was soon followed by other European projects, such as ADLAB PRO, ${ }^{v}$ which ran from 2016 to 2019 and which specifically focused on AD and the profile of the professional delivering these services, the audio describer. Similarly to the ACT project, a survey was first carried out (see section 4 of this article) to map out the situation at the time, pinpoint gaps and needs and find out which skills and competences audio describers need in order to deliver high-quality services efficiently. Unlike the Accessibility Manager for the Scenic Arts, the audio describer was not an entirely new profession and training already existed. Moreover, given the wide variety of audiovisual productions that can be accompanied by $A D$, audio describers can have one or multiple profiles, depending on whether they provide AD for television and/or cinema, for theatre and/or other live events or for museums and/or other forms of static art. Therefore, the curriculum and course structure developed as part of the project were designed to be flexible. On the one hand, the learning outcomes corresponded either to basic skills and competences (for those who had not received any previous training) or to more advanced skills and competences (for audio describers with previous knowledge and/or experience). On the other hand, a structure comprising six different course modules was created so that trainers could opt to train their learners for one or more of the AD modalities mentioned above (see section 5).

In the case of live subtitling, two separate European projects are currently in progress. The first is called Live Text Access (LTA) vi and focuses on intralingual live subtitling, while the other focuses on Interlingual Live Subtitling for Access (ILSA). ${ }^{\text {vii }}$ Both projects are discussed in different contributions in this volume (see Bernabe \& Eugeni; Robert, Schrijver, \& Diels.; Pöchhacker \& Remael) and therefore will not be elaborated on here. Both of these projects follow the blueprint that was created by the ACT consortium: based on an analysis of the current situation in the field, they first identify the skills and competences that intra/interlingual live subtitlers need. These skills and competences are then translated into learning outcomes and a training curriculum. Finally, diverse learning materials are developed that can be implemented in both new and existing courses. The following sections discuss 
Mazur, I., \& Vercauteren, G. (2019). Media accessibility training. Linguistica Antverpiensia, New Series - Themes in Translation Studies, 18, 1-22.

what these courses look like, the skills and competences that they hone, the materials they use, and the types of assessment they propose.

\section{The media accessibility training landscape}

As already mentioned, the first experts in MA were mostly trained internally by the companies or institutions that provide such services and their training was tailored to the needs of a particular organization. Later, institutions of higher education recognized the training niche and began offering courses to prepare MA experts for the world of practice. Given the fact that university training is generally not sufficiently specialized for graduates to be able to seek employment in a variety of settings, the courses taught there were inherently broader in scope than the in-house training offered by companies. Below we attempt to establish the current landscape of MA training, mostly based on the results of two surveys conducted as part of the ADLAB PRO (for AD) and ILSA (for respeaking) projects. A detailed overview of respeaking courses is offered by Romero-Fresco (2012), where he compares on-campus respeaking training with that conducted on-line. An updated overview can be found in this volume (see Eugeni \& Bernabé; Robert et al.). Mazur and Chmiel (in press), on the other hand, provide a snapshot of the training situation for $A D$.

As part of the ADLAB PRO project, a questionnaire was circulated among AD trainers to determine what the $A D$ training landscape looked like at the beginning of 2017. Responses were collected from 86 trainers and covered a total of 192 courses taught both at universities (93 of them) and in professional settings (the remaining 99). Two main conclusions can be derived from the responses: the AD training being offered is quite substantial and it is provided both by academia and the professional world.

A similar survey was conducted in the spring of 2018 as part of the ILSA project among respeaking trainers. Here, however, only five professionals provided their input, representing five courses on intralingual live subtitling (IntraLS) and two courses on interlingual live subtitling (InterLS). This suggests that respeaking is still a niche type of instruction, especially in the interlingual mode.

With regard to $A D$ training, responses were elicited concerning, for example, trainers' profiles, cooperation with visually impaired persons while teaching and the AD types most commonly taught. The respondents described themselves as university teachers (62\%), professional audio describers (55\%) and researchers (49\%). They could select more than one answer, so the results point to the fact that most teachers identify themselves as performing more than one role. The trainers confirmed that they cooperate with visually impaired persons during their classes: $22 \%$ always do it, $23 \%$ do it often and $23 \%$ do it sometimes. The most commonly taught type is film $A D(81 \%)$, followed by museum $A D(55 \%)$, theatre $A D(40 \%)$, and $A D$ for other live events (30\%), with $A D$ of educational materials (20\%) and opera $A D(17 \%)$ also being part of their offering (Mazur \& Chmiel, in press).

In respeaking training, on the other hand, most IntraLS trainers train for television or television and live events (four responses), with only one respondent training exclusively for live events. As for InterLS training, one course focuses on television respeaking only, whereas the other prepares candidates for both television and live events (Robert, Schrijver, \& Diels, 2019, p. 8). 
Mazur, I., \& Vercauteren, G. (2019). Media accessibility training. Linguistica Antverpiensia, New Series - Themes in Translation Studies, 18, 1-22.

Most university AD courses are offered at a master's level (61\%), followed by a bachelor's level (20\%); some of them are stand-alone postgraduate courses (18\%). viii The topic is taught either as a separate module ${ }^{\mathrm{ix}}(41 \%)$ or as part of other courses $(59 \%)$, mainly related to $M A$, translation or AVT (ADLAB PRO 2017, pp. 9-10). The majority of courses are taught face to face $(76 \%)$, with some being offered in the on-line (14\%) or blended learning (10\%) formats. $A D$ modules (or $A D$ components embedded in other courses) tend to be rather short and last less than 10 hours (33\%), 10-20 hours (30\%), 21-30 hours (18\%) and more than 30 hours (18\%).

On the other hand, the ILSA survey for respeaking training showed that, save for one vocational course, all the courses were taught at a master's level in programmes centred on interpreting, AVT and applied linguistics. Three of the IntraLS courses were self-contained, whereas two were part of larger modules on MA. The two InterLS courses were self-contained. As far as course length is concerned, a great disparity was detected: the duration of the courses ranged from 11 to 40 weeks, while the number of contact hours varied between three and 104. All the courses, whether IntraLS or InterLS, combine face-to-face meetings with online instruction and/or an internship (Robert et al., 2019, p. 12).

So far as teaching experience is concerned, $17 \%$ have taught AD for more than 10 years, a little more than half of the AD trainers (57\%) have taught it for three to 10 years and $23 \%$ have taught it for less than three years. As for respeaking, the trainers are less experienced: InterLS has been taught for one or two years, whereas IntraLS has been taught for a maximum of 11 years (Robert et al., 2019, p. 8).

Regarding student numbers for $A D$, university teachers reported that in the previous three years they had taught more than 60 students (49\%), between 41 and 60 (20\%), between 21 and $40(20 \%)$ and fewer than 20 (12\%) (ADLAB PRO, 2017, p. 8). Altogether, the university AD teachers have taught more than 2,000 students, and it is worth noting that this number does not include participants in non-academic courses. On the other hand, the five respeaking trainers have each trained approximately 20 students to date.

The differences between $A D$ training and respeaking training are therefore vast, and they point to the fact that $A D$ training has a much longer tradition and caters to more students than respeaking training.

\section{Current and emerging topics in media accessibility training}

The new developments in MA training have raised a number of fundamental questions, which can be grouped into four broad categories, namely: (1) the skills and competences these new professionals need; (2) the methodologies and pedagogical principles underlying this type of training or, in other words, the way in which MA modules or courses should ideally be designed; (3) the educational materials to be used to train future professionals; and, finally, (4) the assessment criteria by which to evaluate the progress of learners. The literature on the didactics of MA training is still scarce and fragmented, usually focusing on only one particular service. Yet, on the basis of the existing body of knowledge, a few first - partial - answers can tentatively be formulated. 
Mazur, I., \& Vercauteren, G. (2019). Media accessibility training. Linguistica Antverpiensia, New Series - Themes in Translation Studies, 18, 1-22.

\subsection{Skills and competences}

When training prospective MA experts, one of the first considerations is the skills and competences required of such professionals. According to the European Commission (2018, p. 11), competence could be defined as

the proven ability to use knowledge, skills and personal, social and/or methodological abilities, in work or study situations and in professional and personal development,

whereas a skill is

the ability to apply knowledge and use know-how to complete tasks and solve problems.

Skills include the so-called soft or transferable skills, which are

generic capabilities which allow people to succeed in a wide range of different tasks and jobs (Training Agency, 1990, p. 5).

As opposed to hard skills, which are job-specific, soft skills are not linked to any particular profession and, as such, can be transferred from workplace to workplace. The research conducted by the PACTE group (Hurtado Albir, 2017) determined that translation competence involves mostly procedural (knowing how to do things) rather than declarative knowledge (knowing about things). We could assume that the same is true for AD and respeaking, as these practices have an affinity with the translation profession. In order to increase graduates' employability and bridge the university-job market gap, it seems imperative for university education to teach students both hard and soft skills as well as to help them develop their professional competence (rather than just have them acquire declarative knowledge).

Regarding AD, Matamala and Orero (2007) offer an overview of those publications that had by then dealt with the topic, including works by Díaz Cintas (2007), Hyks (2005), Matamala (2006), Navarrete Moreno (1997), Orero (2005) and Vidal (2004). Díaz Cintas (2007) was one of the first to categorize AD competences into four types: (1) linguistic competences; (2) competences related to the content; (3) technological or applied competences; and (4) personal and general competences (after Matamala \& Orero, 2007, pp. 331-332). As far as AD skills are concerned, Fryer (2016) enumerates three main competences: writing, script preparation and delivery. Snyder (2014), on the other hand, mentions four: observation, editing, language, and vocal skills. These proposals, however, are quite general and not based on empirical research. Rather, they seem either to be an extrapolation of skills and competences defined for other (audiovisual) translation types or are based on the practice of AD.

To rectify the situation, the already mentioned ADLAB PRO survey was also meant to find out which skills and competences trainers prioritized in training future audio describers. The results showed that the most commonly taught skill was, as could be expected, AD drafting ( $87 \%$ for academic courses and $91 \%$ for non-academic courses), followed by raising awareness of the needs of the visually impaired $(76 \%$ and $87 \%$ for academic and non-academic courses, respectively). Regarding vocal skills, only $29 \%$ of the academic courses focused on teaching them, as compared to $46 \%$ of the non-academic courses (ADLAB PRO, 2017; Mazur \& Chmiel, in press). 
Mazur, I., \& Vercauteren, G. (2019). Media accessibility training. Linguistica Antverpiensia, New Series - Themes in Translation Studies, 18, 1-22.

In another question the respondents were presented with a list of selected AD competences which they evaluated using a five-point Likert scale (where 5 meant "very important" and 0 signified "unimportant"). The survey showed that the three competences deemed most important, in both university and professional courses, were:

- choosing the most relevant information to describe (4.87)

- knowledge of the needs of the visually impaired (4.87), and

- perfect use of mother tongue (4.70).

These competences were followed by choosing appropriate AD strategies (4.46) and dealing with technical aspects (e.g., editing, timing, text compression) (4.32).

The questionnaire also asked about the importance of soft skills in $A D$ training and the participants were given a list of them from which to choose their answers. All of the skills listed below were considered important:

- efficient work organization and time management ranking (4.45)

- ethics (4.29)

- self-development (4.15)

- teamwork (4.11).

For respeaking, Arumí Ribas and Romero Fresco (2008, pp. 112-116) have proposed a taxonomy of respeaking skills, which they divide into those that are obtained from subtitling or simultaneous interpreting and those that are inherent in respeaking itself. Furthermore, the skills are categorized into those activated before and during respeaking in addition to those pertaining to the source text (ST), the target text (TT) and the process of transition between the two. The taxonomy is fine-grained and includes the following umbrella skills, which are further subdivided into specific skills:

- software-related

- preparation

- strategic

- general ST-related

- general TT-related

- listening comprehension

- analysis, synthesis and reformulation

- synchronization

- multitasking

- live

- production

- awareness of the target audience, and

- delivery.

In addition, Remael and van der Veer (2006) mention a skill that they call "mental pre-editing", that is, anticipating what will and what will not be recognized by the automatic speech recognition (ASR) software. 
Mazur, I., \& Vercauteren, G. (2019). Media accessibility training. Linguistica Antverpiensia, New Series - Themes in Translation Studies, 18, 1-22.

Based on the ILSA survey results, Robert et al. (2019, p. 13) present the skills, or prerequisites, that trainers consider important for successfully performing intra- and interlingual respeaking. The participants' answers were recorded on a Likert scale of 0-4 (where 0 meant "unimportant" and 4 signified "very important"). Both IntraLS and InterLS trainers considered the following skills to be very important, giving each of them four points:

- interaction with speech recognition software

- technical aspects of speech recognition

- multitasking

- extracting the essence of the ST and rephrasing it, and

- knowledge of SL and TL.

These were followed by:

- accurate spelling, grammar and punctuation (3.5 for InterLS; 3.8 for IntraLS)

- turn-taking or overlapping dialogue (3.5 for InterLS; 3.8 for IntraLS)

- awareness of the needs of the deaf and hearing impaired (3.5 for InterLS; 3.4 for IntraLS), and

- knowledge of current affairs (3.5 for InterLS; 2.6 for IntraLS).

The lowest scores were awarded to the skills knowledge of the rules and regulations of companies (2.5 for InterLS; 2.8 for IntraLS) and IT competence (1.5 for InterLS; 2.8 for IntraLS). As evidenced by these results, both InterLS and IntraLS prioritize more or less the same skills, with the exception of the knowledge of current affairs (which is considered more important for InterLS) and IT competence (which is deemed more significant in IntraLS).

It seems that whereas linguistic competence and awareness of the needs of the target groups are important for both $A D$ and respeaking training, in the latter case greater emphasis is placed on technical aspects, such as interacting with the software, which is an indispensable element of any respeaking job. In contrast, although there is specialized software for AD production, it is not crucial to drafting professional $A D$, which may explain why this skill is not emphasized during training. Also, teamwork (or rather pair work, as respeakers usually work in pairs) is of vital importance in respeaking, whereas in $A D$, which is normally considered a solitary activity, it may be important. Indeed, in some settings describers may work in pairs, or even groups of three, when collaborating with a blind consultant.

\subsection{Curriculum design and methodological approaches}

In AD one of the first course ${ }^{x}$ design proposals was offered by Matamala and Orero (2007): it was intended to be part of a postgraduate programme on AVT. The authors start off by defining the competences that should be fostered by the course, the expected learning outcomes and the course content. They also propose a range of practical exercises and assessment methods. In addition to content focused specifically on AD creation, the course included social aspects of $A D$ (e.g., history, intended audience, guidelines and audio-describer profile) and also on the relationship between $A D$ and Translation Studies regarding such concepts as ST and TT equivalence or fidelity. The course was offered first on-line and then in a face-to-face format. 
Mazur, I., \& Vercauteren, G. (2019). Media accessibility training. Linguistica Antverpiensia, New Series - Themes in Translation Studies, 18, 1-22.

Jankowska (2017) presents a detailed description of an AD module as part of a larger AVT programme. The module was designed around nine units, based on topics such as accessibility, awareness-raising and regulations, text editing, translation vs writing, and guidelines and standards or strategies for AD. All the units had a similar structure and involved the following activities: introduction, lecture, reading assignment, quiz, discussion and practical tasks. The module was taught in a blended learning environment, with most of the activities carried out on-line. With the benefit of hindsight, the trainer stressed that she was not convinced that this format was the best option for training audio describers. Apart from the fact that such a learning environment makes it difficult to establish teacher-student rapport similar to that fostered by face-to-face encounters, it is also difficult to imbue the students with what Orero (2005, p. 10) calls "commitment to access for people with disabilities". Indeed, face-to-face classes offer more potential for personal contact with persons with sight loss, which, on the one hand, gives the students an opportunity to know their needs better and, on the other, teaches them that being an audio describer is a job that entails servicing a community (Jankowska, 2017, p. 120).

Apropos methodological approaches, the activities in Jankowska's module (2017) were set within the framework of Laurillard's (2012, p. 96) types of learning, namely, through acquisition, enquiry, practice, production, discussion and collaboration. In fact, the ADLAB PRO survey of $A D$ trainers revealed that the most common type of learning is practice $(91 \%$ of academic and $94 \%$ of non-academic courses included practical exercises), followed by discussion of $A D$ guidelines $(84 \%$ and $78 \%$ of academic and non-academic courses, respectively) and enquiry (in the form of analysing existing ADs). A total of $91 \%$ and $72 \%$ of academic and non-academic courses, respectively, use this type of exercise to provide the students with some AD examples and solutions. Interestingly, learning through acquisition is also quite common, especially in courses taught at universities, where as many as $84 \%$ of them include the presentation of AD theory compared to $58 \%$ of courses taught outside of academia (Mazur \& Chmiel, in press). The difference could be explained by the fact that non-academic courses are by their very nature more practice-oriented and usually suited to the actual needs of a given company or institution, whereas in academia AD is taught both as part of practical classes and of more theoretically or research-oriented courses.

As $A D$ matures as a discipline, new methodological approaches to its training are being proposed. One such proposal has been put forward by Chmiel, Mazur, and Vercauteren (2019), who describe a course design for training audio describers. The procedure draws upon situated and contextualized learning models (Kiraly, 2000, 2005) and is based on the taxonomy of Bloom, Engelhart, Furst, Hill, and Krathwohl (1956), as revised by Krathwohl (2002), and linked to the already mentioned types of learning proposed by Laurillard (2012). The starting point is the definition of learning outcomes, which are then aligned to learning materials, learning methods and assessment types. For example, the first of a number of interconnected learning outcomes could be "The student can name and define the different narrative constituents in a story", which corresponds to the cognitive process of "Remembering" in Bloom's taxonomy and is linked to Laurillard's learning through acquisition. The teaching materials used to achieve this learning outcome could include a presentation and a video and the assessment would be formative and based on a knowledge quiz with open-ended questions. While here the learner's role is rather passive, other learning outcomes trigger Bloom's more advanced cognitive processes (such as "Understand", "Analyse" or "Create") 
Mazur, I., \& Vercauteren, G. (2019). Media accessibility training. Linguistica Antverpiensia, New Series - Themes in Translation Studies, 18, 1-22.

and call for more active involvement on the part of the learners by means of learning through enquiry, discussion or collaboration (Chmiel et al., 2019, p. 333).

This procedure can also be used by AD trainers when designing their own courses; indeed, it has been successfully applied to the creation of the contents of the ADLAB PRO course that encompasses six modules: (1) Introduction and transferable skills; (2) Screen AD; (3) Dynamic performances and events; (4) Static arts and environments; (5) Additional services and specific contexts; and (6) Technological issues and new developments.

With regard to designing respeaking courses, Romero-Fresco (2012, pp. 99-101) discusses three main issues that need to be considered: (1) the interface between respeaking, interpreting and subtitling; (2) the course length; and (3) the software and facilities requirements.

When looked at from the vantage point of the process, respeaking - whether in the intralingual or the interlingual mode - bears a similarity to simultaneous interpreting as it involves the concurrent processes of listening, analysing, producing and monitoring the output. On the other hand, when looked at from the point of view of the product, respeaking can be linked to subtitling, as the end-result is speech-recognition-based subtitles mainly aimed at the deaf and hard-of-hearing community. A question then arises whether respeaking modules should be part of interpreting programmes or AVT ones. Both options have their challenges for the student population: interpreters-to-be would have to master the principles of AVT and unlearn certain behaviours (such as, for example, speaking in a pleasant voice, because the speech recognition software would prefer them to speak in a robot-like manner), while would-be subtitlers would have to master the art of interpreting. Intuitively, one could argue that the former solution is more effective, as mastering simultaneous interpreting seems more demanding in terms of time and cognitive effort than mastering the principles of $\mathrm{SDH}$. In any case, nowadays, most respeaking modules are part of AVT rather than interpreting programmes (Romero-Fresco, 2012, p. 100). Also, it seems that such modules are better suited to postgraduate rather than undergraduate programmes, because the former are more specialized and as such require more advanced skills.

As for course duration, the optimum module length seems to be from three to six months, with one meeting per week, for students who have preferably completed their training in either translation or interpreting and have some knowledge of SDH (Romero-Fresco, 2012, p. 100). The author stresses, however, that shorter courses can also be effective, but these would have to place greater emphasis on autonomous learning by the students. For example, the respeaking module at Universitat Autònoma de Barcelona comprised five two-hour face-toface meetings, which were interspersed with intensive self-study, which is "pedagogically more important than the actual number of contact training hours" (Romero-Fresco, 2012, p. 100). Such autonomous practice allows the students to master specific skills on their own (such as setting up and managing their own voice profiles with speech recognition software) before moving on to the next item in the curriculum.

Technology plays a very important role in respeaking, usually requiring the use of speech recognition software and a subtitling programme. Screencasting software (e.g., Camtasia Studio, Captivate, HyperCam or ScreenCam) may also be useful in a respeaking course. The first two are used by the students to practise respeaking and the ILSA survey revealed that all 
the trainers who responded use both an ASR system (e.g., Newton Dictate, Dragon Naturally Speaking) and subtitling software (e.g., Wincaps, FAB Subtitler Live) in their modules. On the other hand, screen recording programmes help the trainer to evaluate the students' performance: the respoken subtitles are recorded as displayed on their screens (without the broadcast being respoken) along with their voices respeaking the content to speech recognition software. In addition to assessing the students' performance in real time, the trainer may look at the recorded output later and evaluate it more thoroughly. In this respect, screen recording is not a skill that is really required for respeaking, but it is one that students need to master when training to become respeakers, particularly for assessment purposes. For a detailed overview of the different types of technology and their application in a respeaking course see Romero-Fresco (2012).

When designing a course in respeaking, one may also take into account whether training should be restricted to subtitles in one language (monolingual) or more languages (multilingual). The latter case is more complex, because it requires the trainer to provide dictation exercises in the languages spoken by the students, although non-language-specific instruction is also feasible when introducing the principles of respeaking and the software. Practising with language-specific dictation exercises, the students may compile lists of common errors for each language which can be used by the trainer in future training (RomeroFresco, 2012, p. 102). Another factor to consider is whether the training should be intra- or interlingual. In the case of the latter mode, students would have to be proficient in another language. Also, the interlingual training is more demanding, because, in addition to all the required skills for intralingual respeaking, the students would also have to transfer the meaning of the ST into the respoken subtitles, which places great demands on their cognitive load.

Regarding the course content in IntraLS, as reported by Robert et al. (2019) and based on the ILSA survey results, three of the five trainers focus on the theory of respeaking in their classes, whereas the other two place greater emphasis on respeaking techniques. Four trainers mention the importance of ASR software, two of whom stress the significance of error detection. Other commonly taught skills include setting up ASR software profiles, adding vocabulary, using macros, dictation, correct enunciation, practising the division of attention (between listening and speaking), plus subtitling and editing. Courses for InterLS are designed in a similar way, although more focus is placed on interpreting skills, and such courses are structured around learning outcomes, which can range from general - for instance, "The students should be able to respeak and correct any given speech (intralingual)" - to very detailed outcomes categorized into "Knowledge" (e.g., "The student knows various speech recognition systems and their limitations"), "Skills" (e.g., "The student can predict terminological issues and can prepare for them in advance by adapting the system dictionary, using templates or macros") and "Social competences" (e.g., "The student knows different types of target group using live subtitles and understands their needs").

\subsection{Training materials}

Once a course is designed, it needs to be filled with content in the form of educational materials. A number of $A D$ trainers have shared their ideas for exercises or samples of the materials they use. For example, Matamala and Orero (2007) describe a range of exercises, 
Mazur, I., \& Vercauteren, G. (2019). Media accessibility training. Linguistica Antverpiensia, New Series - Themes in Translation Studies, 18, 1-22.

including preparatory (such as describing facial expressions, kitchen utensils, and fabrics or patterns), and more advanced exercises (e.g., describing both a linear and a complex movie scene). Sadowska (2014) provides some exercises for describing press illustrations, whereas Remael and Vercauteren (2007) focus on teaching students content selection for film AD and suggest that the exposition phase of a film is "especially interesting from a didactic point of view" (p. 77), because it is usually within the first ten minutes or so that the essential narrative clues for the whole film are presented. Jankowska (2017) also offers some ideas for activities, exercises and reading assignments for all of the units included in her blended course (see section 5.2). To date, the most comprehensive $A D$ training materials have been created by ADLAB PRO and are available on the project's website. These include reading lists, core videos explaining the basic concepts, additional videos dealing with more in-depth issues and also tasks and trainer's guides. All in all, 438 pieces of educational material have been created and distributed across the course's six modules (see section 5.2). The materials are open access and can be customized to suit the needs of a particular trainer or course. In a similar vein, for interlingual live subtitling a course structure and training materials are to be developed as part of the ILSA project, whereas the LTA project is planning the development of such a structure and materials for intralingual live subtitling.

For respeaking, Arumí Ribas and Romero Fresco (2008) propose a range of exercises to which students can be exposed to acquire the given skills (see section 5.1). For example, to develop preparation skills the authors suggest an exercise in training the respeaking software for efficient performance. This involves compiling relevant vocabulary lists, dictating them to the software and testing whether the training of the software has been successful. To analyse the ST properly, detect the sense units and reduce them for processing in the working memory (segmentation), an exercise is suggested that includes having students listen to a text (without taking notes) and then asking them questions about its content. Arumí Ribas and RomeroFresco (2008) offer a wide range of exercises that help to develop the following skills: synthesis and reformulation, multitasking, dealing with a live situation, and delivery. Further sample exercises that target specific learning outcomes are presented by Romero-Fresco (2012).

\subsection{Assessment}

Assessment is a complex issue that can be looked at from a variety of angles. One of the most thorough overviews of assessment methods in translator training is that presented by Kelly (2005, pp. 130-149). Normally, we associate assessment with final assessment, although we can also talk of aptitude testing prior to course enrolment or intermediate assessment. It can also be either formative (measuring the progress of a student) or summative (measuring how much the student has learned during a course). In addition to evaluation performed by the trainer, peer assessment and self-assessment could also be included. Whatever the purpose or the mode, assessment should always be aligned with the learning outcomes in order to verify whether these have been achieved by the learner. In addition, assessment can also be related to competence testing by certifying bodies to ascertain whether a particular person meets the required standards for a given profession.

Assessment is related not only to skills and competences or professional standards but also to the issue of quality. Quality seems to be most problematic, especially in AD. In live subtitling errors can be quantified and the accuracy rate measured - for example, by using the NER 
Mazur, I., \& Vercauteren, G. (2019). Media accessibility training. Linguistica Antverpiensia, New Series - Themes in Translation Studies, 18, 1-22.

model for the intralingual modality that considers edition and recognition errors or the NTR model for the interlingual variety. The NTR model also takes into account translation errors as regards both content and form (Romero-Fresco \& Pöchhacker, 2017). The ILSA survey revealed that three out of the five trainers resorted to focusing on the trainee's accuracy rate in the assessment process and that the assessment mode is either continuous only or continuous combined with a final exam or an internship (Robert et al., 2019, p. 12).

The situation is more complex for $A D$, because choices related to content selection, the language used to describe it and the amount of text are often subjective and can be related to genre or even to an individual product, and therefore any potential errors are more difficult to pinpoint and quantify. Fryer (2019) has suggested adapting the rating scales and assessment protocols used in interpreting for evaluating AD quality; Cabeza Cáceres (2017) has proposed a checklist type of $A D$ assessment that includes three macro-criteria: content, language and sound. Some of the criteria, however, are based on AD guidelines, which may no longer apply, given the results of reception studies or more flexible approaches to $A D$, such as the functional approach, where content selection, the adopted $A D$ strategies and $A D$ wording largely depend on the type of the audio-described production, its purpose, function and the audience design (Mazur, 2019). Therefore, it would seem that a comprehensive model for assessing the quality of $A D$ that could also be applied in training set-ups has yet to be developed.

The complexity of $A D$ assessment also emerges from the description of the teaching practices shared by $A D$ trainers, who remain rather vague on the topic. For example, Matamala and Orero (2007) discuss the way in which students' tasks are evaluated in very general terms (i.e., what gets evaluated in $A D$ are: content selection, the chosen vocabulary and the overall effect), whereas Jankowska (2017, p. 118) states that "[a]ssessment was one of the most challenging aspects of the module". She mentions that the answers in quizzes were graded automatically, whereas the remainder of the tasks were evaluated manually by the trainer, which was very time-consuming and not always successful, although no specifics are provided. However, neither Matamala and Orero (2007) nor Jankowska (2017) enumerates the specific criteria used for evaluation.

When it comes to types of assessment, the $\operatorname{ADLAB~PRO~(2017,~p.~10)~survey~revealed~that~the~}$ weighting in academic courses included active participation in the class (83\%), a final project involving $A D$ drafting (71\%), homework completion (68\%), passing test(s) (27\%) and writing a research paper (15\%). To sum up, assessment - especially in the context of AD training - has to date not been treated thoroughly and requires further research.

\section{Contributions in this volume}

The collection of articles presented in this special issue of Linguistica Antverpiensia, New Series - Themes in Translation Studies devoted to media accessibility training, reflects the considerable advances that have been made in the current state of the art of research into MA pedagogics and didactics.

In the first article, Gian Maria Greco zooms in on a fundamental question that precedes and transcends the curricular design of any module or course on (media) accessibility. Arguing that most present-day MA courses focus mainly on practical, strategic and instrumental skills, often 
Mazur, I., \& Vercauteren, G. (2019). Media accessibility training. Linguistica Antverpiensia, New Series - Themes in Translation Studies, 18, 1-22.

ignoring the theoretical perspective that should underlie these skills as one of the core competences any accessibility expert should have, he calls for the integration of critical learning spaces that foster a universalist approach to MA. These spaces should equip MA trainees with a tool to approach their object of study through the critical lens of Accessibility Studies. In doing so, they will serve to avoid reducing accessibility services to a mere aid to overcoming a disability and to see them instead as a way of reflecting on otherness. By means of some concrete examples from current projects and courses, the author illustrates how these critical learning spaces can be integrated into the MA curriculum.

The next two articles translate this universalist approach into concrete examples. In the first of them, Pablo Romero-Fresco starts from the observation that in the film-making industry accessibility is predominantly an afterthought, something that is added only once the film has been completed and all content and stylistic changes have been made. As he points out, only $0.01 \%$ of the budget of the most popular award-winning films of the 21st century was devoted to translation and accessibility, even though the new audiences these translated and accessible versions can reach in some cases account for half of the revenue. Accessible Film Making (AFM) and the new professional profile of the Director of Accessibility and Translation (DAT) should change this situation, making sure that accessibility is taken into account at every single stage of the film production process. As pointed out by the author, training in AFM is still very scarce, and he goes on to present two possible courses in AFM: a MOOC that offers an introduction to accessible film-making and a fully fledged master's course in accessible filmmaking.

A similar line of thought underlies the contribution by Xiaochun Zhang, in which she reports on a part of the EU-funded Accessible Culture and Training (ACT) project that introduced two new professional profiles: Accessibility Manager and Accessibility Coordinator. The basic reasoning underlying the project was that accessibility to any cultural event should also encompass the provision of information before the event and facilitate access to and inside the venue. Again, rather than adding accessibility features once the event has been fully organized, they should be included as an integrated part of the creative process and of the wider approach to inclusion that a venue should embrace and embody. The project therefore proposed the creation of two new professionals who would oversee the complete accessibility process, either as a permanent member of the staff (Accessibility Coordinator) or as an external expert (Accessibility Manager). Based on the structure developed by the European Certification and Qualification Association (ECQA), the article discusses the skills needed at every stage of the process and how they can be integrated into separate but complementary skill sets for these two professional profiles.

In the following articles, the focus shifts from a holistic, overarching perspective on accessibility to a more specific one. Each of these contributions looks at one of the various access services and tries to unveil the skills and competences required to shape the different professional profiles, which could, in turn, inform the development of training courses.

The first profile scrutinized is that of the live subtitler, a professional working in a constantly developing environment, in terms of both the tools used to create the subtitles (from traditional and Velotype keyboards to ASR technology) and the services requested (intralingual or interlingual). According to Carlo Eugeni and Rocío Bernabé, this dynamic and 
Mazur, I., \& Vercauteren, G. (2019). Media accessibility training. Linguistica Antverpiensia, New Series - Themes in Translation Studies, 18, 1-22.

diverse reality results in a plethora of terms that are used depending on the context in which the subtitles are created or the system that is is used to produce them. In addition to their analysis of the terminological affluence, they look at the current practices of training intralingual live subtitlers so that they can identify the skills and competences that are included in curricula and compare them with those identified by means of an on-line survey carried out in the framework of the LTA project. This comparison and the ensuing insights into the existing mismatch between the skills and competences taught and those required by the labour market result in a skill set for the intralingual live subtitler that can serve as a basis for the future development of curricula and training materials.

The next two articles turn the attention to an even more recent profile added to the professional field of subtitling, namely that of the interlingual live subtitler, which is the object of study in another EU-funded project, called Interlingual Live Subtitling for Access (ILSA). Taking a similar approach to that adopted by Eugeni and Bernabé, Isabelle Robert, Iris Schrijver and Ella Diels give an account of a survey that was developed within the framework of the ILSA project to form an idea of who intralingual and interlingual live subtitlers are. With this survey, distributed among professionals, the authors wanted to obtain clearer insights into current professional practice so as to find out how practitioners who currently work as live subtitlers had been trained. Although it proved difficult to compare the results between the groups of intralingual and interlingual live subtitlers, given the limited number of responses, one of the conclusions that can be drawn from the article is that there is a clear need for a comprehensive live subtitling course in which all the skills and competences identified by the survey can be taught.

A first step towards the realization of such a course - which is the ultimate aim of the ILSA project - is presented in the contribution by Franz Pöchhacker and Aline Remael, who theoretically analyse the practice of interlingual live subtitling (ILS) as a task that resembles various other forms of translation, predominantly prepared subtitling and intralingual live subtitling, and simultaneous interpreting. Following a comprehensive overview of the various (sub)processes and (sub)skills involved in ILS, the authors propose a competence model that is centred on five main competences, namely: (1) technical-methodological competence; (2) linguistic and cultural competence; (3) world knowledge and subject-matter competence; (4) (inter)personal competence; and (5) professional competence. This model serves as a basis for the following steps of the project, in which the competences will be linked to concrete learning outcomes that, in turn, can inform the creation of learning materials.

As has already been explained earlier in this introduction, the LTA and ILSA projects are not the first endeavours to define the profiles of accessibility professionals and to design and develop courses to train future practitioners. A similar approach was taken by the ADLAB PRO project, which focused on the profession of the audio describer. Just like the projects on live subtitling, a first stage of ADLAB PRO consisted of obtaining a clear overview of the current practice of $A D$ training in Europe as a basis for the subsequent development of a curriculum and concrete course materials. Nuria Mendoza and Anna Matamala present the findings of the ALDAB PRO survey that was carried out in Spain. Combining the results from a questionnaire that was disseminated among audio describers, $A D$ service providers and end users, with input from semi-structured interviews with $A D$ trainers, the authors draw a picture of (a) the skills and competences that are deemed important by the different stakeholders 
Mazur, I., \& Vercauteren, G. (2019). Media accessibility training. Linguistica Antverpiensia, New Series - Themes in Translation Studies, 18, 1-22.

and (b) those that are currently taught in Spanish AD courses. As was the case in the studies on the skills and competences of live subtitlers, the article concludes that there is a mismatch between what is being taught and what is deemed most important, a mismatch that will duly have to be taken into account when designing curricula for future AD courses.

In the article by María Luque and Olga Soler the focus shifts from the profile of the audio describer of pre-recorded content to that of the audio describer for art museums. The authors first describe a study carried out in museums in Spain, France, the United Kingdom and the United States in order to derive a picture of the current profiles of the professionals who are providing $A D$ in these environments. The findings show that these profiles are quite diverse, in terms of both the professionals' educational background and their relationship to the museums where/for which they work. In the second part of their article, the authors elaborate a proposal for the training of one of the profiles identified, namely that of people who graduated in Translation (Studies). The proposal is rooted in the social-constructivist approach to translator training developed by Kiraly (2000) and in recent pedagogical studies that underline the importance of authentic experiences in translator training, more particularly the inclusion of internships. The proposal starts from the premise that trainees have already acquired the basic translator competences in previous training and that the internship itself serves to develop a so-called meta-competence in which all these basic competences converge.

Determining which skills and competences are needed to acquire a certain professional profile is a prerequisite for the development of any course. Once they are translated into concrete learning outcomes, the pedagogical and methodological question of how they can be taught comes into play. Indeed, once we know what we need to teach, the following step is to decide how to teach it and with which materials. This issue is considered in the following contributions of this volume, which take the form of practice reports. As mentioned in the previous paragraph, new pedagogies recommend including authentic experiences in the training of future translators and exactly such an experience is described in Agnieszka Szarkowska's contribution on project-based learning in subtitler training.

The article starts with a comprehensive overview of the existing literature on the projectbased learning approach in translator training and its limited application in subtitler training. After that, the focus shifts to a real project the author's students had to complete during a subtitling course. As becomes apparent from the article, integrating authentic projects in AVT training has undeniable advantages, but it also introduces difficulties and disadvantages. First, working with real-life projects creates a time pressure that is usually not present when adopting more traditional approaches with smaller-scale exercises. Depending on the exact context, this may be a problem that affects only the students, or the students and the trainer or all of the parties involved, namely, students, trainer and client. In addition, as this practice report shows, authentic projects also seem to place higher demands on students' soft skills such as organizing the work and teamwork. If not handled well, this may significantly increase the trainer's workload both before and during the project. Consequently, careful thought has to be given to how and when the project work will be assessed so as to avoid overburdening the trainer. 
Mazur, I., \& Vercauteren, G. (2019). Media accessibility training. Linguistica Antverpiensia, New Series - Themes in Translation Studies, 18, 1-22.

The second practice report included in the volume is by Anna Jankowska and it focuses on AD. The professional profile of the audio describer and, hence, the skills and competences she or he needs have only very recently been established. It is not surprising, therefore, that didactic approaches to teaching them are still very limited and that trainers often have to develop their own practices and materials. In her approach, generally framed as it is within Biel's (2013) integrative functional approach, the author presents a collection of learning materials and exercises that introduce learners to the practice of $A D$, make them aware of the various ways in which $A D$ can be created, and show them where they can find guidance on making $A D s$ and what the strengths and limitations of these guidelines are. The last group of exercises presented caters for an emergent reality in AD - but one that is more longstanding in other areas of translation - namely that of collaborative work. Indeed, in reality, the deadlines for creating $A D$ are often very tight, which means that various describers have to work on one project at the same time. This again calls for different skills, the organizational and collaborative.

As already pointed out, research into assessment is still very limited, and it is only scarcely dealt with in this volume, making it probably one of the most wide-open avenues for further research in MA training. The contribution by Pablo Romero-Fresco, Sabela Melchor-Couto, Hayley Dawson, Zoe Moores and Inma Pedregosa reports on an accessibility problem that arose in the United Kingdom in 2016, when the government refused to fund respoken subtitles for disabled students because respeaking was not an officially recognized profession. This article delineates an official standard - called LiRICS - whose aim is to guarantee that respeaking services are of a sufficiently high quality. Although the goal of this standard is to lead to a certification for the respeaking profession, it will be granted only if the respeaker meets well-defined performance criteria. In this respect, the article gives an overview of existing research on the assessment of respeaking quality and explains how one particular assessment procedure, the NER model (Romero-Fresco \& Martínez, 2015), has been incorporated into the on-line assessment used for the LiRICS certification process.

The last article in this volume approaches the topic from a completely different angle and, rather than looking at training in MA, it looks at the use of MA in training in higher education. Wing Shan Chan, Jan-Louis Kruger and Stephen Doherty report on the findings of a study that looked at the impact of subtitles on cognitive load and learning in first-language and secondlanguage educational contexts. With the advent of on-line learning platforms such as Coursera and Khan Academy, we have seen an exponential increase in the use of audiovisual educational materials. If these materials are to reach the widest possible audience and offer learning opportunities to as many learners as possible, they have to be subtitled. As this can be both time-consuming and not very cost-effective, the authors have looked into the possibility of adding automatically created subtitles to educational videos as a practical way to overcome those issues. The problem with these subtitles is that they may contain serious errors, of both content and style, and therefore they require considerable post-editing effort, resulting again in temporal and financial drawbacks. The central question in their article, therefore, is whether subtitles of a lower-than-publishable quality can be used, that is, to what extent the raw output of the automatically generated subtitles can be used in educational contexts and how they affect the learners' cognitive load and learning results. 
Mazur, I., \& Vercauteren, G. (2019). Media accessibility training. Linguistica Antverpiensia, New Series - Themes in Translation Studies, 18, 1-22.

\section{Conclusion}

MA is slowly but steadily becoming part and parcel of audiovisual products and live events, which means that the demand for properly trained professionals who can offer high-quality access services will increase in the future. As discussed in the overview of the state of the art, the training of these professionals requires that various elements are taken into careful consideration: (1) skills and competences have to be identified; (2) a didactic approach to training them has to be identified; (3) training materials have to be developed; and, as a final step, (4) trainers have to assess whether or not all the necessary skills and competences have been acquired.

The articles collected in this volume considerably advance the present situation in various respects. While the sets of skills and competences that have previously been proposed in the literature were mostly reports of one course, based on personal knowledge and experience of the trainer, the sets defined within the framework of ACT, ADLAB PRO, ILSA and LTA, as presented here, are the result of extensive international surveys in which all stakeholders were involved. Although in some cases the number of respondents was very limited, this approach offers a much more general panorama of the skills and competences that are considered important for the respective professions. However, various questions remain, particularly with regard to how these skills and competences should be trained. Recent developments in pedagogy advocate that training and training materials should be situated in real-life contexts and that learners should be given the opportunity to take responsibility for their own learning. However, as the contribution by Szarkowska shows, this approach may also present considerable obstacles and further research is needed to determine how situated and student-centred learning can be integrated optimally in MA training.

Another development that has a profound impact on how MA - or any other subject, for that matter - is taught is the rapid technological evolutions we are witnessing today. Indeed, as Laurillard (2012) puts it: "knowledge technologies shape what is learned by changing how it is learned" (p. 3). And sound insights into how technology can improve training are needed to prevent us simply translating traditional training methods into new formats rather than harnessing the full potential that these new formats offer. In addition, we have to be aware of the pitfalls that these new technological developments can present. Romero-Fresco's and Zhang's contributions, for example, mention the use of MOOCs. Generally speaking, on-line training methods such as MOOCs have undeniable advantages: they offer materials in both visual and verbal formats that cater for different learning styles and they allow learners to process new content at their own pace. In other words, they offer the flexibility and autonomy needed for a student-centred approach to learning. On the other hand, they also present various drawbacks. For instance, Gütl, Hernández Rizzardini, Chang, and Morales (2014) report that attrition rates in MOOCs are on average 10-20 per cent higher than in face-to-face education (p. 38) and that in some cases fewer than 10 per cent of participants complete the course (p. 37). Other drawbacks that are frequently mentioned are the very limited contact between trainers and learners and the ensuing lack of feedback (Bali, 2014). In other words, when designing MOOCs for MA training, attention has to be paid to these shortcomings and further research should be carried out to find out how they can be overcome and how technology in general can be harnessed for education so as to truly advance training. 
Mazur, I., \& Vercauteren, G. (2019). Media accessibility training. Linguistica Antverpiensia, New Series - Themes in Translation Studies, 18, 1-22.

Finally, assessment is one of the areas in the field of MA training where, clearly, a lot still has to be done. In the field of live subtitling, the NER (intralingual live subtitling) and NTR (interlingual live subtitling) models (see section 5.4) already provide valuable tools with which to measure accuracy and to quantify the errors made, but similar instruments are still nonexistent in the field of AD. Section 5.4 identified three broad evaluation criteria, namely, content, style and amount of $A D$, but further research is urgently needed to find out how these can be operationalized into measurable parameters: How can we evaluate whether or not a describer selected the appropriate content? Which elements determine whether or not the style of the AD suits the product? What measures should be used to evaluate whether or not the amount of $A D$ that is provided is neither too high nor too low? And how can all these quality indicators be combined into a comprehensive assessment model that takes into account all the specificities of $A D$ ?

\section{References}

ADLAB PRO. (2017). Assessment of current $A D$ training practices [Report]. Retrieved from http://www.adlabpro.eu/wp-content/uploads/2017/12/20170608_uam_io1_report.pdf

Arumí Ribas, M., \& Romero Fresco, P. (2008). A practical proposal for the training of respeakers. JosTrans, 10, 106-127.

Bali, M. (2014). MOOC pedagogy: Gleaning good practice from existing MOOCs. Journal of Online Learning and Teaching, 10(1), 44-56.

Bloom, B. S., Engelhart, M. D., Furst, E. J., Hill, W. H., \& Krathwohl, D. R. (1956). Taxonomy of educational objectives: The classification of educational goals. Handbook 1: Cognitive domain. London, England: Longmans.

Cabeza-Cáceres, C. (2017, March). Professional audio descriptions: Same film, same assignment = same quality? Paper presented at Advanced Research Seminar on Audio Description ARSAD, Barcelona, Spain. Abstract retrieved from http://grupsderecerca.uab.cat/arsad/sites/grupsde recerca.uab.cat.arsad/files/arsad2017_abstracts_final.pdf

Cerezo Merchán, B. (2019). Audiovisual translator training. In L. Pérez-González (Ed.), The Roudledge handbook of audiovisual translation (pp. 468-482). New York, NY: Routledge.

Chmiel, A., Mazur, I., \& Vercauteren, G. (2019). Emerging competences for the emerging profession: A course design procedure for training audio describers. The Interpreter and Translator Trainer, 13(3), 326-341. doi:10.1080/1750399X.2019.1656408

Díaz Cintas, J. (2007). Por una preparación de calidad en accesibilidad audiovisual. TRANS. Revista de traductología, 11, 45-59. doi:10.24310/TRANS.2007.v0i11.3097

European Commission. (2018). European Skills/Competences, Qualifications and Occupations (ESCO). Retrieved from https://ec.europa.eu/esco/portal/escopedia/Competence?resetLanguage= true\&newLanguage $=e n$

Fryer, L. (2016). An introduction to audio description: A practical guide. London, England: Routledge.

Fryer, L. (2019). Quality assessment in audio description: Lessons learned from interpreting. In E. Huertas-Barros, S. Vandepitte \& E. Iglesias-Fernández (Eds.), Quality assurance and assessment practices in translation and interpreting (pp. 155-177). IGI Global. doi: 10.4018/978-1-5225$5225-3$

Greco, G. M. (2018). The nature of accessibility studies. Journal of Audiovisual Translation, 1(1), 205232. Retrieved from https://www.jatjournal.org/index.php/jat/article/view/51

Gütl, C., Hernández Rizzardini, R., Chang, V., Morales M. (2014). Attrition in MOOC - Lessons learned from drop-out students. In L. Uden, J. Sinclair, Y.-H. Tao \& D. Liberona (Eds.), Learning technology for education in cloud: MOOC and Big Data (pp. 37-48). London, England: Springer.

Hurtado Albir, A. (Ed.). (2017). Researching translation and interpreting competence by PACTE group. Amsterdam, The Netherlands: John Benjamins. 
Mazur, I., \& Vercauteren, G. (2019). Media accessibility training. Linguistica Antverpiensia, New Series - Themes in Translation Studies, 18, 1-22.

Hyks, V. (2005). Audio Description and translation. Two related but different skills. Translating Today, 4, 6-8.

Jankowska, A. (2017). Blended learning in Audio Description training. Między Oryginałem a Przekładem, 38, 101-124. doi:10.12797/MOaP.23.2017.38.05

Kelly, D. (2005). A handbook for translator trainers: A guide to reflective practice. Manchaster, England: St. Jerome.

Kiraly, D. (2000). A social constructivist approach to translator education: Empowerment from theory to practice. Manchester, England: St. Jerome.

Kiraly, D. (2005). Project-based learning: A case for situated translation. Meta: Journal des traducteurs, 50(4), 1098-1111. doi:10.7202/012063ar

Krathwohl, D. R. (2002). A revision of Bloom's taxonomy: An overview. Theory into Practice, 41(4), $212-$ 218. doi:10.1207/s15430421tip4104_2

Laurillard, B.D. (2012). Teaching as a design science. Abingdon, England: Routledge. doi:10.4324/9780203125083

Matamala, A. (2006). La accesibilidad en los medios: aspectos lingüísticos y retos de formación. In R. Pérez-Amat \& Á. Pérez-Ugena (Eds.), Sociedad, integración y televisión en España (pp. 293-306). Madrid, Spain: Laberinto.

Matamala, A., \& Orero, P. (2007). Designing a course on audio description and defining the main competences of the future professional. Linguistica Antverpiensia New Series, 6, 329-344. Retrieved from https://lans-tts.uantwerpen.be/index.php/LANS-TTS/index

Mazur, I. (2019, June). A functional approach to audio description: Proposal of a framework. Paper presented at the 8th Media for All International Conference: Complex Understandings, Stockholm, Sweden. Abstract retrieved from https://www.tolk.su.se/english/media-for-all8/programme/abstracts/a-functional-approach-to-audio-description-1.429418

Mazur, I., \& Chmiel, A. (in press). Audio description training: A snapshot of the current practices. The Interpreter and Translator Trainer, 14(4).

Navarrete Moreno, F. J. (1997). Sistema AUDESC: El arte de hablar en imágenes. Integración: Revista sobre ceguera y deficiencia visual, 23, 70-75. Retrieved from https://www.once.es/dejanosayudarte/la-discapacidad-visual/revista-integracion

Orero, P. (2005). Audio description: Professional recognition, practice and standards in Spain. Translation Watch Quarterly, 1(1), 7-18. Retrieved from http://www.translocutions.com/. tsi/twq/

Remael, A., \& van der Veer, B. (2006). Real-time subtitling in Flanders: Needs and teaching. In C. Eugeni \& G. Mack (Eds.), Intralinea Special Issue: Respeaking. Retrieved from http://www.intra linea.org/specials/article/Real-Time_Subtitling_in_Flanders_Needs_and_Teaching.

Remael, A., \& Vercauteren, G. (2007). Audio describing the exposition phase of films: Teaching students what to choose. Trans: Revista de traductologia, 11, 73-93. doi: 10.24310/TRANS. 2007.v0i11.3099

Robert, I., Schrijver, I., \& Diels, E. (2019). Trainers' and employers' perceptions of training in intralingual and interlingual live subtitling: A survey study. Journal of Audiovisual Translation, 2(1), 1-25. Retrieved from https://www.jatjournal.org/index.php/jat

Romero-Fresco, P. (2012). Respeaking in translator training curricula: Present and future prospects. The Interpreter and Translator Trainer, 6(1), 91-112. doi: 10.1080/13556509.2012. 10798831

Romero-Fresco, P., \& Martínez, J. (2015). Accuracy rate in live subtitling: The NER model. In J. Díaz Cintas \& R. Baños (Ed.), Audiovisual Translation in a global context: Mapping an ever-changing landscape (pp. 28-50). London, England: Palgrave Macmillan. doi:10.1057/9781137552891_3

Romero-Fresco, P. (2018). In support of a wide notion of media accessibility: Access to content and access to creation. Journal of Audiovisual Translation, 1(1), 187-204. Retrieved from https://www.jatjournal.org/index.php/jat 
Mazur, I., \& Vercauteren, G. (2019). Media accessibility training. Linguistica Antverpiensia, New Series - Themes in Translation Studies, 18, 1-22.

Romero-Fresco, P., \& Pöchhacker, F. (2017). Quality assessment in interlingual live subtitling: The NTR model. Linguistica Antverpiensia, New Series: Themes in Translation Studies, 16, 149-167. Retrieved from https://lans-tts.uantwerpen.be/index.php/LANS-TTS/index

Sadowska, A. (2014). Audiodeskrypcja do ilustracji w prasie: Wskazówki dla trenerów szkolących audiodeskryptorów [Audio description for press illustrations: Guidelines for trainers]. Przekładaniec, 28, 124-139. doi:10.4467/16891864PC.14.009.1716

Snyder, J. (2014). The visual made verbal: A comprehensive training manual and guide to the history and applications of audio description. Arlington, VA: American Council of the Blind.

Training Agency. (1989). Enterprise in higher education: Key features of the EHE proposals. Sheffield, England: Employment Department Group.

Vidal, A. (2004). La audiodescripción: Una herramienta de ayuda para los ciegos. Integración: Revista de la Asociación de Implantados Cocleares, 32, 30-31. Retrieved from http://integracion. implantecoclear.org/index.php 
Mazur, I., \& Vercauteren, G. (2019). Media accessibility training. Linguistica Antverpiensia, New Series - Themes in Translation Studies, 18, 1-22.

i https://www.un.org/development/desa/disabilities/convention-on-the-rights-of-persons-withdisabilities.html

ii https://eur-lex.europa.eu/legal-content/EN/TXT/?uri=COM\%3A2015\%3A0615\%3AFIN

iii http://pagines.uab.cat/easit/en

iv Project Reference No.: 2015-1-ES01-KA203-015734, http://pagines.uab.cat/act

$\checkmark$ Project Reference No.: 2016-1-IT02-KA203-024311, www.adlabproject.eu

vi Project Reference No.: 2018-1-DE01-KA203-004218, www.Itaproject.eu

vii Project Reference No.: 2017-1-ES01-KA203-037948, http://ka2-ilsa.webs.uvigo.es

viii Some of the results in the ADLAB PRO report (2017) do not add up to 100, as the figures have been rounded (down).

ix In this article we use the term "module" to refer to a unit of teaching and "programme" to refer to a group of modules. The term "course" is used in both meanings, depending on the context. 